\title{
Uterine Blood Flow and Uterine Renin Secretion
}

\author{
Thomas F. Ferris, Jay H. Stein, and Jeffrey Kauffman \\ From the Department of Medicine, Ohio State University College of Medicine, \\ Columbus, Ohio 43210
}

A в S T R A C T Experiments were carried out in pregnant nephrectomized rabbits to determine the relationship between uterine blood flow and uterine renin secretion. Uterine blood flow was measured by the percentage distribution of radioactive microspheres injected into the left ventricle which lodged in uterus and placenta, and cardiac output was measured by dye dilution. In 40 animals, $24 \mathrm{hr}$ after nephrectomy, uterine blood flow was $4.7 \pm 0.4 \%$ of cardiac output and absolute flow $32.4 \pm 3$ $\mathrm{ml} / 100 \mathrm{~g}$ per min. Plasma renin activity (PRA) in uterine vein, $994 \pm 182 \mathrm{ng} / 100 \mathrm{ml}$ per $\mathrm{hr}$, was higher than in carotid artery, $832 \pm 143(P<0.025)$. With reduction of uterine blood flow from $4.7 \pm 0.5$ to $1.95 \pm 0.3 \%$ of cardiac output and absolute flow from $30.8 \pm 4.6$ to $8.8 \pm 2 \mathrm{ml} / 100 \mathrm{~g}$ per min, uterine vein PRA rose from $1434 \pm 234$ to $4430 \pm 300(P<0.001)$, and carotid artery PRA from $1009 \pm 200$ to $2300 \pm 350(P<0.01)$. Hemorrhagic hypotension caused uterine vein PRA to increase from $913 \pm 293$ to $3638 \pm 1276(P<0.001)$ and carotid artery PRA from $774 \pm 252$ to $1730 \pm 433 \quad(P<0.01)$. Uterine blood flow expressed as a percentage of cardiac output remained constant after hemorrhage, 5.5 \pm 0.9 and $6.3 \pm 0.8 \%$, although absolute flow fell from $37 \pm 7.7$ to $29 \pm 3.6 \mathrm{ml} / 100 \mathrm{~g}$ per min because of the large fall in cardiac output which occurred.

Angiotensin, $10 \mathrm{ng} / \mathrm{kg}$ per min, caused no significant change in blood pressure or cardiac output but increased uterine blood flow from $4.1 \pm 0.6$ to $8.4 \pm 1 \%(P<0.005)$ of cardiac output with absolute flow increasing from $37.4 \pm 7$ to $73.2 \pm 10 \mathrm{ml} / 100 \mathrm{~g}$ per $\min (P<0.001)$. The increase in uterine blood flow during angiotensin was abolished by the prior administration of propranolol. Isoproterenol, $0.5 \mu \mathrm{g} / \mathrm{min}$, increased uterine blood flow from $3.5 \pm 0.6$ to $6.4 \pm 1.2 \%$ of cardiac output $(P<0.02)$ with absolute flow increasing from $25 \pm 5$ to $51 \pm 12 \mathrm{ml} /$ $100 \mathrm{~g}$ per $\min (P<0.05)$. Norepinephrine, $500 \mathrm{ng} / \mathrm{min}$, caused no significant change in uterine blood flow.

These studies were presented in part at the American Society of Nephrology Meeting in Washington, November 1971.

Received for publication 17 March 1972 and in revised form 14 July 1972.
These findings suggest that uterine renin might be involved in regulating uterine blood flow, secretion being increased in response to a reduction in flow with the resultant rise in circulating or local angiotensin, through beta adrenergic stimulation, increasing uterine blood flow.

\section{INTRODUCTION}

Although renin has been found in the pregnant uterus of rabbits (1), dogs (2), and humans (3), and demonstrated to be synthesized in tissue culture by both myometrial and endometrial cells (4), its role in the physiology of pregnancy remains unknown. It seems unlikely that it is the source of the high plasma renin activity $(P R A)^{1}$ of pregnancy since uterine renin, at least in the rabbit, does not respond to changes in extracellular fluid volume (5) whereas aldosterone secretion during pregnancy responds appropriately to changes in sodium intake (6). One hypothesis is that uterine renin functions as a regulator of uterine blood flow. In an attempt to evaluate this possibility, experiments were carried out in pregnant nephrectomized rabbits to define the relationship between changes in uterine blood flow and uterine renin secretion. The results indicate that a reduction in uterine blood flow by either hemorrhage or uterine artery ligation increases uterine renin secretion, and angiotensin increases uterine blood flow through stimulation of the beta adrenergic nervous system.

\section{METHODS}

Australian white rabbits were utilized between the 24th and 28th day of gestation. $24 \mathrm{hr}$ before the experiment, a bilateral nephrectomy was carried out and the animals kept without food or water. In all experiments the animals were anesthetized with Nembutal, a midline neck incision was made for placement of a tracheostomy tube and catheterization with 180 polyethylene tubing of the right jugular vein and both carotid arteries. The left carotid catheter was threaded into the left ventricle, the presence of the

\footnotetext{
${ }^{1}$ Abbreviation used in this paper: PRA, plasma renin activity.
} 


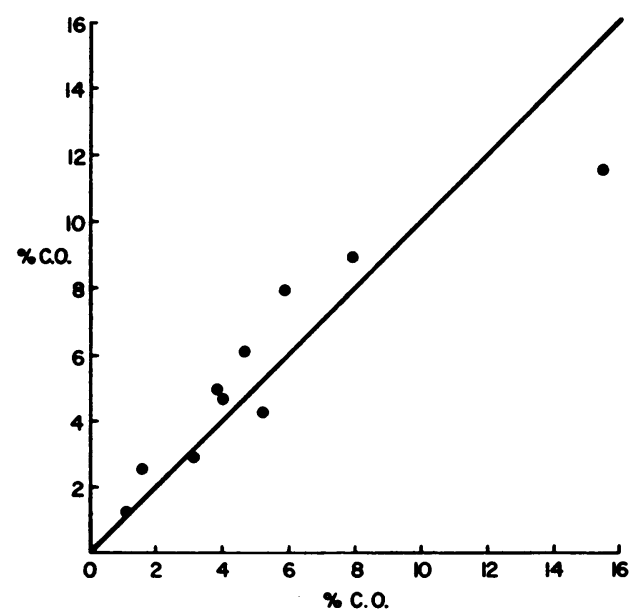

FIGURE 1 A comparison in 10 animals of two determinations of uterine blood flow expressed as a percentage of cardiac output (C.O.). Initial uterine flow is plotted on the abscissa and the second value obtained within $1 \mathrm{~min}$ is plotted on the ordinate.

catheter in the ventricle was verified by ventricular pressures recorded by a Statham strain gauge, (Statham Instruments, Inc., Oxnard, Calif.) and recorded on a Sanborn polygraph. (Sanborn Div., Hewlett-Packard Co., Palo Alto, Calif.) Cardiac output was measured by injection of $1 \mathrm{ml}$ Cardio-Green dye into the jugular vein and blood withdrawn from the right carotid catheter through a cuvette densitometer. The dead space of the catheter and densitometer was less than $1 \mathrm{ml}$ and blood was withdrawn at a rate of $25 \mathrm{ml} / \mathrm{min}$. Blood was reinjected into the animal following obtaining the dilution curve. The mean of two dilution curves was obtained for each calculation of cardiac output.

Uterine blood flow was measured by the injection into the left ventricle of approximately 200,000 radioactive microspheres ${ }^{2} 19 \pm 2 \mu$ diameter, labeled with either ${ }^{85} \mathrm{Sr}$ or ${ }^{141} \mathrm{Ce}$. A $0.25 \mathrm{ml}$ solution of microspheres containing $0.01 \mu \mathrm{Ci} / \mathrm{ml}$ was diluted with $10 \%$ dextran to a volume of $2.5 \mathrm{ml}$ in a plastic syringe. Next, $2 \mathrm{ml}$ was injected into the animal and the remaining $0.5 \mathrm{ml}$ was diluted with $9.5 \mathrm{ml} 10 \%$ dextran and counted in a Packard auto-gamma counter (Packard Instrument Co., Downers Grove, Ill.) The radioactivity remaining in the syringe following the injection was subtracted from the total. Cardiac output was measured before and after each injection of microspheres. After completion of the experiment, the uterus and placentas were removed, weighed, and digested in concentrated $\mathrm{HCl}$. The radioactivity in a portion of the uterine and placenta digest was determined. ${ }^{85} \mathrm{Sr}$ was counted at the $0.510 \mathrm{Mev}$ peak and ${ }^{141} \mathrm{Ce}$ was counted at the $0.145 \mathrm{Mev}$ peak. No correction was necessary for the ${ }^{85} \mathrm{Sr}$ counts but $15 \%$ of the ${ }^{85} \mathrm{Sr}$ counts was subtracted to obtain the true ${ }^{141} \mathrm{Ce}$ counts. The percentage of the total counts injected which lodged in the uterus and placenta was calculated and uteroplacental blood flow expressed as a percentage of cardiac output. No radioactivity was detected in the fetuses or uterine vein after the injection. Absolute uteroplacental blood flow, $\mathrm{ml} / \mathrm{min}$ per $100 \mathrm{~g}$, was calculated from the cardiac output.

\footnotetext{
${ }^{2} 3 \mathrm{M}$ Company, St. Paul, Minn.
}

\section{T. F. Ferris, J. H. Stein, and J. Kauffman}

Infusions of angiotensin (Hypertensin, Ciba Pharmaceutical Co., Summit, N. J.), norepinephrine (Levophed, Burroughs Wellcome Co., Research Triangle Park, N. C.), isoproterenol (Isuprel, Winthrop Laboratories, New York) were given through the jugular vein. In the propranolol experiments $5 \mathrm{mg}$ intravenous Inderal (Ayerst Laboratories, New York) was given $30 \mathrm{~min}$ before beginning the angiotensin infusion.

Uterine blood flow was reduced by ligating both uterine arteries close to their origin from the iliac artery; uterine flow is maintained through collateral vessels, primarily the ovarian arteries, after such a ligation. In the hemorrhage experiments, $50 \mathrm{ml}$ blood was withdrawn from the carotid artery. $15 \mathrm{~min}$ after hemorrhage cardiac output, uteroplacental blood flow, uterine vein, and carotid artery renin activities were determined. After all experiments the viability of the fetuses was established. Those experiments in which most of the fetuses were not alive at the completion of the experiment were discarded. In the few experiments where uterine and placental blood flows were calculated when fetal death was evident, counts in the placenta were less than $1 \%$ of the injected amount during both control and experimental periods, indicating that the fetal death had probably occurred before the start of the experiment.

The uterine arteries and veins were exposed through a low abdominal incision. Samples of blood $(4 \mathrm{ml})$, obtained from uterine vein and carotid artery for renin determinations, were replaced with equal volumes of Albumisol. PRA was measured by a modification of the method of Pickens, Bumpus, Lloyd, Smeby, and Page $(7,8)$.

Results are expressed as mean \pm standard error. Statistical analysis of the data was carried out by paired $t$ test.

\section{RESULTS}

Fig. 1 demonstrates the reproducibility in measuring uterine blood flow by the microsphere method in 10 animals. Over the range of uterine blood flow from 1.1 to $15.5 \%$ of cardiac output mean flow difference obtained by injecting microspheres within $1 \mathrm{~min}$ was $1.3 \pm 0.4 \%$. The range of uterine blood flow was due in part to the variation in the number of fetuses present. They ranged from 2 to 12 fetuses and uterine blood flow expressed as a percentage of cardiac output was usually proportional to the number of placentas present. However, since microspheres measure instantaneous flow, uncontrolled factors such as uterine contraction, the degree of viability of the fetuses, and the level of anesthesia would have an effect. However, in a given animal the reproducibility was good and mean flow in the various groups of animals was quite similar.

The results of all experiments are presented in Table I and Fig. 2.

Angiotensin infusion. Angiotensin (10 ng/kg per min) caused a slight but insignificant rise in arterial pressure from $102 \pm 7.3$ to $110 \pm 7.5 \mathrm{~mm} \mathrm{Hg}$ with no change in cardiac output, $690 \pm 29$ before and $707 \pm 51$ $\mathrm{ml} / \mathrm{min}$ after angiotensin. Uteroplacental blood flow significantly increased during angiotensin from 4.1 to $8.4 \%$ of cardiac output $(P<0.005)$ and absolute flow from $37 \pm 7.1$ to $73 \pm 10 \mathrm{ml} / 100 \mathrm{~g}$ per $\min (P<0.001)$. 
TABLE I

The Effect of Various Experimental Maneuvers upon Arterial Pressure, Cardiac Output, Uteroplacental Blood Flow, and Uterine Renin Secretion

\begin{tabular}{|c|c|c|c|c|c|c|c|c|c|c|c|c|}
\hline \multirow{3}{*}{$\begin{array}{l}\text { Exp. } \\
\text { No. }\end{array}$} & & & & & \multicolumn{4}{|c|}{ Plasma renin activity } & \multirow{2}{*}{\multicolumn{2}{|c|}{$\begin{array}{l}\text { Uteroplacental } \\
\text { blood flow }\end{array}$}} & \multirow{2}{*}{\multicolumn{2}{|c|}{$\begin{array}{l}\text { Uteroplacental } \\
\text { blood flow }\end{array}$}} \\
\hline & \multicolumn{2}{|c|}{ MAP } & \multicolumn{2}{|c|}{ Cardiac output } & Carot & rtery & Ute & rein & & & & \\
\hline & $\mathrm{C}$ & $\mathrm{E}$ & C & $\mathrm{E}$ & $\mathrm{C}$ & $\mathrm{E}$ & C & $\mathrm{E}$ & $\mathrm{C}$ & $\mathrm{E}$ & C & $\mathrm{E}$ \\
\hline & & & & & & $n g / 10$ & per $h r$ & & & & $m l / 10$ & er $\min$ \\
\hline Angiotens & infusio & & & & & & & & & & & \\
\hline 1 & 90 & 117 & 731 & 583 & 640 & 480 & 800 & 560 & 1.5 & 6.4 & 12.3 & 41.9 \\
\hline 2 & 90 & 75 & 740 & 975 & 720 & 480 & 1000 & 640 & 3.0 & 5.0 & 27 & 57.8 \\
\hline 3 & 120 & 120 & 658 & 887 & 1200 & 780 & 2000 & 990 & 6.0 & 6.8 & 36.6 & 56 \\
\hline 4 & 120 & 130 & 533 & 509 & 2000 & 1800 & 2400 & 2100 & 1.6 & 14.2 & 7.1 & 55.4 \\
\hline 5 & 120 & 93 & 790 & 693 & 3000 & 2100 & 3000 & 2400 & 4.3 & 7.6 & 50 & 78 \\
\hline 6 & 83 & 70 & 556 & 591 & 1200 & 800 & 1300 & 640 & 8.0 & 11.0 & 71 & 105 \\
\hline 7 & 90 & 100 & 769 & 704 & 1100 & 800 & 1100 & 1000 & 4.3 & 13.1 & 47.5 & 132 \\
\hline 8 & 127 & 137 & 733 & 698 & 4800 & 4000 & 6400 & 4000 & 5.1 & 7.1 & 72 & 97 \\
\hline 9 & 122 & 133 & 780 & 902 & 400 & 400 & 200 & 480 & 3.4 & 8.3 & 30 & 84 \\
\hline 10 & 57 & 123 & 610 & 535 & 2200 & 2100 & 2200 & 2400 & 3.5 & 4.7 & 21 & 25 \\
\hline Mean & 102 & 110 & 690 & 707 & 1726 & 1374 & 2040 & 1521 & 4.1 & 8.4 & 37 & 73 \\
\hline SEM & \pm 7.3 & \pm 7.5 & \pm 29 & \pm 51 & \pm 425 & \pm 360 & \pm 553 & \pm 367 & \pm 0.62 & \pm 1.03 & \pm 7.1 & \pm 10.1 \\
\hline$P$ & & & & & & & & & & & & \\
\hline Angioten & with $p$ & anolol & & & & & & & & & & \\
\hline 1 & 97 & 85 & 752 & 730 & & & & & 3.5 & 2.8 & 26.3 & 20.4 \\
\hline 2 & 132 & 107 & 1067 & 961 & & & & & 4.5 & 5.2 & 48 & 48 \\
\hline 3 & 83 & 83 & 1050 & 1040 & & & & & 2.5 & 2.3 & 26 & 24 \\
\hline 4 & 110 & 113 & 949 & 879 & & & & & 4.6 & 3.4 & 43 & 30 \\
\hline 5 & 90 & 80 & 889 & 825 & & & & & 2.5 & 2.8 & 22 & 23 \\
\hline 6 & 108 & 108 & 676 & 620 & & & & & 3.6 & 2.7 & 24.3 & 16.7 \\
\hline Mean & 103 & 96 & 897 & 843 & & & & & 3.5 & 3.2 & 31.6 & 28.0 \\
\hline SEM & \pm 7.1 & \pm 6.1 & \pm 65 & \pm 63 & & & & & \pm 0.37 & \pm 0.43 & \pm 4.5 & \pm 4.6 \\
\hline$P$ & $x+1$ & $x 0.1$ & $<0$ & $5^{200}$ & & & & & 20.08 & 20.80 & & \\
\hline Norepine & rine infu & & & & & & & & & & & \\
\hline 1 & 100 & 97 & 689 & 621 & 100 & 400 & 100 & 480 & 3.1 & 1.2 & 19.2 & 6.7 \\
\hline 2 & 43 & 57 & 746 & 688 & 320 & 1000 & 480 & 640 & 5.4 & 2.8 & 36.4 & 18 \\
\hline 3 & 77 & 63 & 683 & 730 & 240 & 400 & 80 & 1100 & 4.6 & 4.8 & 35 & 38.5 \\
\hline 4 & 80 & 93 & 659 & 776 & 400 & 640 & 480 & 320 & 5.1 & 3.8 & 31 & 27.2 \\
\hline 5 & 140 & 130 & 1054 & 540 & 480 & 480 & 400 & 720 & 1.4 & 3.0 & 14.8 & 16.6 \\
\hline 6 & 97 & 105 & 617 & 540 & 240 & 120 & 160 & 800 & 7.4 & 9.9 & 28 & 35 \\
\hline Mean & 89.5 & 90.8 & 741 & 651 & 296 & 506 & 283 & 676 & 4.5 & 4.25 & 27.4 & 23.6 \\
\hline SEM & \pm 13.0 & \pm 11.1 & \pm 64.8 & \pm 40.7 & \pm 54.7 & \pm 120 & \pm 77.7 & \pm 110 & \pm 0.8 & \pm 1.23 & \pm 3.5 & \pm 4.9 \\
\hline$P$ & 工 & 工и, & $20 \pi, 0$ & $1+6.0$ & 工宊, & $1+20$ & s... & & 10.0 & & & \\
\hline Isoproter & & & & & & & & & & & & \\
\hline 1 & 88 & 60 & 574 & 506 & 320 & 320 & 320 & 480 & 2.8 & 3.8 & 10.6 & 17.5 \\
\hline 2 & 73 & 77 & 619 & 522 & 160 & 160 & 160 & 160 & 4.5 & 7.4 & 27 & 38 \\
\hline 3 & 97 & 95 & 820 & 724 & 200 & 200 & 200 & 320 & 1.8 & 2.9 & 13.1 & 20 \\
\hline 4 & 97 & 93 & 787 & 1092 & 320 & 400 & 320 & 650 & 2.3 & 7.6 & 21 & 82 \\
\hline 5 & 90 & 78 & 975 & 1536 & 400 & 400 & 480 & 480 & 3.8 & 5.3 & 36 & 81 \\
\hline 6 & 119 & 110 & 863 & 524 & 240 & 280 & 280 & 320 & 5.9 & 11.2 & 42 & 66 \\
\hline Mean & 94 & 86 & 773 & 817 & 273 & 293 & 293 & 401 & 3.5 & 6.4 & 25 & 51 \\
\hline SEM & \pm 6.2 & \pm 7.1 & \pm 62 & \pm 170 & \pm 36 & \pm 41 & \pm 46 & \pm 70 & \pm 0.6 & \pm 1.23 & \pm 5.1 & \pm 12 \\
\hline$P$ & & & & & & & & & & & & \\
\hline Uterine a & ery ligat & & & & & & & & & & & \\
\hline 1 & 130 & 90 & 645 & 321 & 600 & 3200 & 1800 & 5600 & 5.6 & 1.4 & 35.8 & 4.6 \\
\hline 2 & 83 & 67 & 698 & 310 & 960 & 1300 & 960 & 1300 & 3.5 & 2.4 & 24.5 & 4.3 \\
\hline 3 & 105 & 98 & 649 & 652 & 1300 & 2800 & 1600 & 4000 & 3.6 & 3.3 & 24 & 21 \\
\hline 4 & 135 & 112 & 719 & 480 & 2000 & 2400 & 2400 & 4000 & 8 & 3.2 & 57.5 & 15.4 \\
\hline 5 & 130 & 77 & 639 & 590 & 1100 & 3000 & 1200 & 7200 & 2.9 & 0.8 & 18 & 4.5 \\
\hline 6 & 93 & 83 & 531 & 484 & 420 & 1600 & 480 & 2500 & 3.6 & 1.2 & 18 & 6.0 \\
\hline 7 & 108 & 87 & 531 & 469 & 680 & 800 & 1600 & 6400 & 4.4 & 1.5 & 25 & 7 \\
\hline Mean & 114 & 90.3 & 645 & 468 & 1009 & 2300 & 1434 & 4430 & 4.7 & 1.95 & 30.8 & 8.8 \\
\hline SEM & \pm 6.29 & \pm 4.55 & \pm 28 & \pm 56 & \pm 200 & \pm 350 & \pm 234 & \pm 800 & \pm 0.54 & \pm 0.34 & \pm 4.6 & \pm 2.0 \\
\hline$P$ & $=0$ & & & & $=200<$ & & & & & & 170 & \\
\hline Hemorrhe & ic hypot & & & & & & & & & & & \\
\hline 1 & 105 & 73 & 521 & 816 & 800 & 1200 & 960 & 2400 & 2.4 & 3.5 & 12.4 & 28 \\
\hline 2 & 93 & 80 & 598 & 461 & 400 & 2100 & 1100 & 1600 & 2.3 & 6.4 & 14.1 & 29 \\
\hline 3 & 80 & 62 & 535 & 350 & 320 & 1600 & 130 & 1600 & 4.7 & 4.3 & 25 & 15 \\
\hline 4 & 93 & 92 & 1034 & 540 & 1280 & 1360 & 240 & 480 & 0.6 & 3.2 & 6.6 & 31 \\
\hline 5 & 102 & 53 & 873 & 285 & 240 & 480 & 400 & & 1.8 & 3.1 & 15.7 & 8.8 \\
\hline 6 & 95 & 72 & 540 & 230 & 400 & 480 & 1000 & 3000 & 8 & 10.3 & 43.2 & 23.7 \\
\hline 7 & 90 & 47 & 676 & 469 & 320 & 3200 & 440 & 16000 & 10.5 & 8.5 & 71 & 40 \\
\hline 8 & 157 & 77 & 406 & 659 & 640 & 1300 & 480 & 1100 & 7.2 & 5.0 & 29 & 33 \\
\hline 9 & 113 & 63 & 594 & 249 & 160 & 320 & 200 & 480 & 10.1 & 4.2 & 75 & 13 \\
\hline 10 & 107 & 63 & 446 & 298 & 200 & 240 & 320 & 1600 & 7.0 & 8.5 & 35 & 29 \\
\hline 11 & 77 & 58 & 935 & 383 & 800 & 2600 & 600 & 4800 & 8.5 & 12.8 & 98 & 60 \\
\hline Mean & 103 & 72 & 667 & 450 & 774 & 1730 & 913 & 3638 & 5.5 & 6.3 & 37 & 29 \\
\hline SEM & \pm 6.25 & \pm 4.6 & \pm 58 & \pm 48 & \pm 252 & \pm 433 & \pm 293 & \pm 1276 & \pm 0.9 & \pm 0.8 & \pm 7.7 & \pm 3.6 \\
\hline$P$ & & & & & & & & & & & & \\
\hline
\end{tabular}

C, control period; E, experimental period; MAP, mean arterical blood pressure; C.O., cardiac output. 


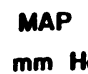

c.o.

$\mathrm{mm}$ Hg

$\mathrm{ml} / \mathrm{min}$
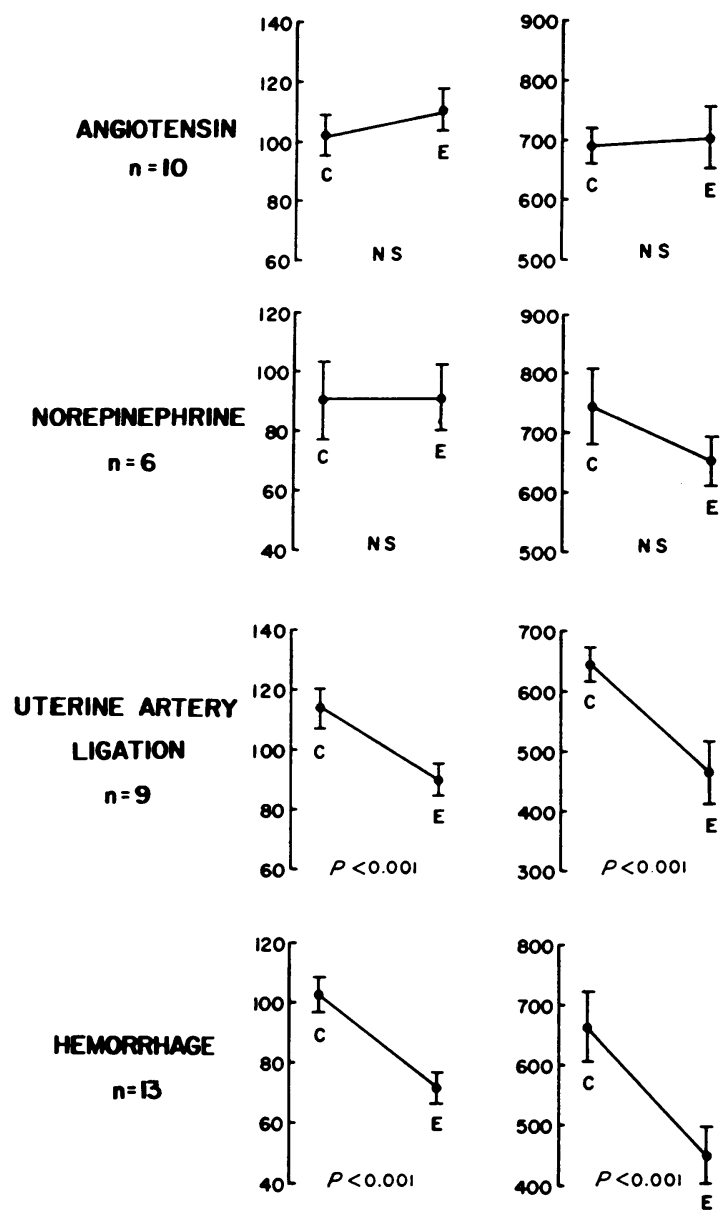
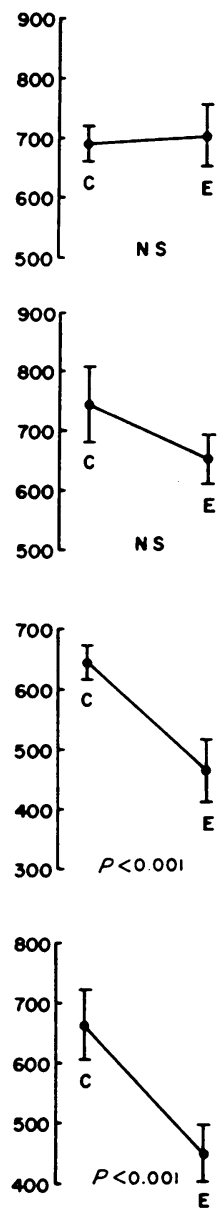
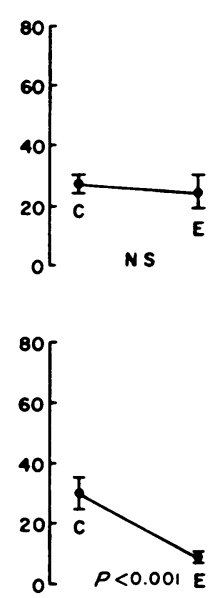

UTEROPLACENTAL

$\mathrm{ml} / \mathrm{min}$
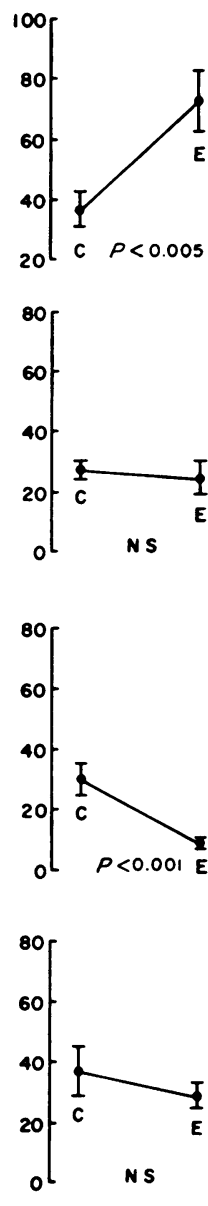

BLOOD FLOW
PRA

UTERWE VEIN

PRA

$\mathrm{ng} / 100 \mathrm{ml}$ per $\mathrm{hr}$
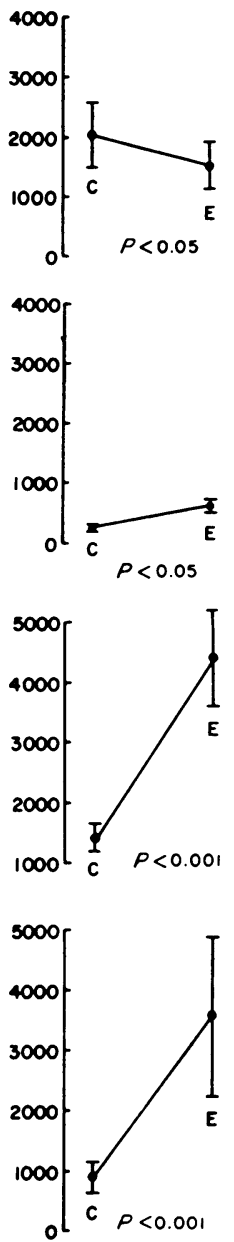
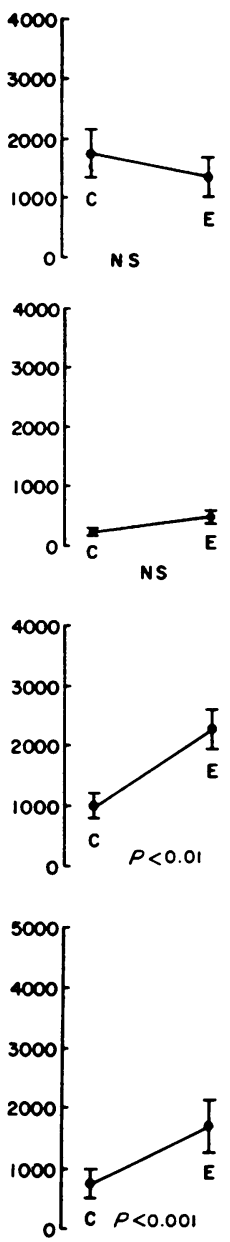

FIGURE 2 The effect of angiotensin, norepinephrine, uterine artery ligation, and hemorrhagic hypotension upon mean arterial blood pressure (MAP), cardiac output (C.O.), uteroplacental blood flow, and PRA in uterine vein and carotid artery. Values are expressed as mean \pm SEM.

After $30 \mathrm{~min}$ of angiotensin, there was a fall in uterine vein and carotid artery PRA, the former from 2040 \pm 550 to $1521 \pm 346$ and the latter from $1726 \pm 425$ to $1374 \pm 360 \mathrm{nl} / 100 \mathrm{ml}$ per $\mathrm{hr}$. The changes were significant $(P<0.05)$ only in uterine vein. In all experiments except one uterine vascular resistance, calculated by dividing arterial pressure by uteroplacental flow, fell during angiotensin. When propranolol, $5 \mathrm{mg}$. was given intravenously $30 \mathrm{~min}$ before angiotensin, no significant change in uterine blood flow occurred, 3.5 $\pm 0.37 \%$ before and $3.2 \pm 0.43 \%$ after angiotensin (Fig. 3).

To determine if similar changes occurred in rabbits not previously nephrectomized, experiments were carried out in intact pregnant rabbits. In seven animals angiotensin caused a rise in relative, $3.09 \pm 0.51$ to 6.14 $\pm 1.1 \%(P<0.025)$, and absolute, $22.5 \pm 4.4$ to $47 \pm 10.7$ $\mathrm{ml} / \mathrm{min}(P<0.05)$, uterine blood flow. In six intact animals given propranolol, uterine flow was $5.2 \pm 1 \%$ before and $4.6 \pm 0.84 \%$ after angiotensin.

Norepinephrine infusion. In six experiments in which norepinephrine $(500 \mathrm{ng} / \mathrm{min}$ ) was infused, there was no significant change in arterial pressure or cardiac output. The mean fall in cardiac output from 741 \pm 65 to $651 \pm 41 \mathrm{ml} / \mathrm{min}$ is due primarily to the large fall which occurred in experiment 5. Uteroplacental flow expressed both as a percentage of cardiac output and in absolute values was unchanged during norepinephrine. PRA rose in both carotid artery and uterine 
vein although the changes are significant only in uterine vein $(P<0.05)$.

Isoproterenol. Isoproterenol, $0.5 \mu \mathrm{g} / \mathrm{min}$, caused a small but insignificant reduction in mean arterial pressure from 94 to $86 \mathrm{~mm} \mathrm{Hg}$ with no significant change in cardiac output. Uteroplacental blood flow increased from 3.5 to $6.4 \%$ of cardiac output $(P<0.02)$ and absolute flow from $25 \pm 5$ to $51 \pm 12 \mathrm{ml} / 100 \mathrm{~g}$ per min $(P<0.05)$ (Fig. 3). No significant change in PRA occurred during isoproterenol.

Uterine artery ligation. After bilateral uterine artery ligation, blood flow is maintained through the circular collateral system involving the ovarian arteries. After ligation there was a significant fall in both arterial blood pressure, $114 \pm 6.3$ to $90 \pm 4.6 \mathrm{~mm} \mathrm{Hg}(P<0.01)$, and cardiac output, $645 \pm 28$ to $468 \pm 57 \mathrm{ml} / \mathrm{min}(P<$ $0.005)$. This finding is unexplained. There was little blood loss or dissection during the ligation procedure. Uteroplacental blood flow fell from $4.7 \pm 0.5$ to 1.95 $\pm 0.3 \%(P<0.001)$ of the cardiac output and absolute flow from 30.8 to $8.8 \mathrm{ml} / 100 \mathrm{~g}$ per $\min (P<0.001)$. $30 \mathrm{~min}$ after ligating the uterine arteries PRA had increased significantly in both uterine vein, $1436 \pm 234$ to $4430 \pm 800(P<0.001)$ and carotid artery, $1009 \pm 200$ to $2300 \pm 350(P<0.001)$. The rise in carotid artery PRA would indicate that absolute uterine renin secretion increased during the period of ligation. In spite of the reduction in flow the fetuses were viable at the completion of the experiment.

Hemorrhagic hypotension. Following hemorrhage mean arterial pressure fell from $103 \pm 6$ to $72 \pm 0.5 \mathrm{~mm}$ $\mathrm{Hg}(P<0.001)$ and cardiac output from $664 \pm 58$ to $450 \pm 48 \mathrm{ml} / \mathrm{min}(P<0.001)$. With hemorrhage there was a striking increase in uterine vein PRA, $913 \pm 283$ to $3628 \pm 1276(P<0.001)$, and in carotid artery, 774 \pm 252 to $1730 \pm 430 \quad(P<0.001)$. Although absolute uteroplacental blood flow fell from $37 \pm 8$ to $29 \pm 4 \mathrm{ml} /$ $100 \mathrm{~g}$ per min, the per cent of cardiac output to the uterus remained unchanged, $5.5 \pm 0.9 \%$ before and 6.3 $\pm 0.8 \%$ after hemorrhage. Similar experiments carried out in four nonpregnant rabbits demonstrated PRA levels $80 \mathrm{ng} / 100 \mathrm{ml}$ per hr or less $24 \mathrm{hr}$ after nephrectomy with no change $1 \mathrm{hr}$ after hemorrhagic hypotension.

A comparison of renal and uterine blood flow with hemorrhage was made in four pregnant animals not previously nephrectomized. Renal blood flow fell from $26.6 \pm 3.7 \%$ of cardiac output to $16 \pm 3.2 \%$ following hemorrhage, in contrast to uterine blood flow which remained constant, $4.6 \pm 1.2$ to $4.8 \pm 1.1 \%$.

\section{DISCUSSION}

Methods of measuring uterine blood flow have been hampered by the multiple blood supply to the organ. A modified Fick principle utilizing nitrous oxide $(9)$ or 4 -

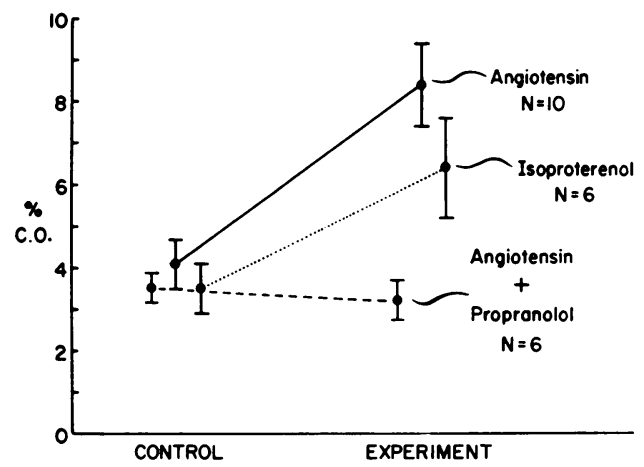

FIgure 3 A comparison of the changes in uterine blood flow, expressed as a percentage of cardiac output (C.O.), during an infusion of angiotensin, isoproterenol, and angiotensin with propranolol. Values are plotted as mean \pm SEM.

aminoantipyrine (10) has been used in pregnant ewes and dogs, but these methods are unsatisfactory in small animals because of the need for serial blood samples. Radioactive microspheres which do not cross the capillary bed are ideally suited for measuring blood flow to organs such as the uterus. The reproducibility of the method with repetitive doses of microspheres is good and the values obtained are similar to those obtained by direct measurement. Duncan (11), utilizing radioactive microspheres, has recently reported uterine blood flow in rabbits to be $27 \mathrm{ml} / \mathrm{min}$, slightly lower than in our experiments. Barcroft and Rothschild, by total collections from uterine veins. found uterine blood flow in rabbits to be $30 \mathrm{ml} / \mathrm{min}$ after the 24th day of gestation (12).

The experiments we report demonstrate that in the nephrectomized pregnant rabbit alterations in uterine blood flow are associated with large changes in uterine renin secretion. With reduction in flow induced by either uterine artery ligation or hemorrhage, there was a striking rise in uterine renin secretion with an increase in uterine vein and carotid artery PRA. Since arterial PRA differences have not been demonstrated, carotid PRA would be similar to uterine artery PRA.

Although extrarenal sites of renin other than uterus have been described $(13,14)$, the high concentrations of renin in pregnant rabbit uterus, higher PRA in uterine vein than carotid artery, and three- to fourfold rise in uterine vein PRA after uterine artery ligation or hemorrhage, makes the uterus the evident source of renin in the nephrectomized pregnant rabbit. A rise in PRA has been found after sustained hemorrhagic hypotension in nonpregnant dogs (15), but we were unable to demonstrate any rise in PRA in nephrectomized nonpregnant rabbits maintained hypotensive for up to 1 hr. In the nephrectomized dog the rise in PRA occurs only after 4-6 hr of severe hypotension when necrosis of blood vessel walls is thought to have occurred. The present experiments were carried out in rabbits since 
uterine renin concentration, similar to renal renin, is higher in rabbits than in other species (16).

There was a wide range of values of PRA in pregnant rabbits following nephrectomy and the levels did not correlate with control uterine blood flow or blood pressure. A similar wide variability in PRA has been described in pregnant dogs (17) and humans (18). Differences in substrate concentration known to be elevated with pregnancy might in part account for the variability. In contrast, PRA $24 \mathrm{hr}$ after nephrectomy in the nonpregnant rabbit is virtually undetectable (5).

No explanation of the higher PRA in carotid artery than uterine vein in seven animals is apparent, but in only two of these animals did carotid PRA remain higher than uterine vein PRA in the experimental period. Similar findings have been described under basal conditions when comparing renal A-V PRA differences $(19,20)$.

Whether uterine renin is identical with renal renin or represents an isoenzyme is not clear. Molecular weights determined by gel filtration are the same and the enzymes are identical with respect to mobility on disc electrophoresis but small (Michaelis constant) $K_{m}$ differences have been demonstrated (21). From a physiological standpoint this difference has little significance since both generate angiotensin from endogenous substrate. Although renin substrate concentrations were not measured in the present studies, the changes in PRA were too rapid and the differences in PRA across the uterus too large to be explained by changes in substrate concentration.

Although angiotensin has a variable vasoconstrictor effect upon various vascular beds, vasoconstriction being most potent in the vessels of the skin, splanchnic region, and kidney, with less effect in skeletal muscle and heart (22), the present finding of vasodilatation in uterine circulation with angiotensin is unique. A similar rise in uterine blood flow with a pressor dose of angiotensin has been reported in pregnant dogs and ewes when measured by electromagnetic flow probes (23). In contrast, norepinephrine caused no change in uteroplacental blood flow and slight but insignificant increases in uterine vascular resistance. The fact that the increase in uterine blood flow with angiotensin was blocked by propranolol indicates that angiotensin stimulates beta adrenergic fibers in the uterus. The effect of angiotensin in certain vascular beds is known to be dependent upon the autonomic nervous system (24-26). In the hand and foot, vasoconstriction with angiotensin is due mainly to its sympathetic effect and is suppressed by alpha adrenergic blocking drugs. In vitro the effect of angiotensin on guinea pig ileum is enhanced by anticholinesterase drugs and diminished by atropine (27).

The uterus has a rich autonomic innervation (28) and pharmacological studies have confirmed the presence of alpha and beta receptors in human uterus (29). Previous studies of the effect of sympathetic activity have involved measurements only of myometrial contractility. The increase in uterine blood flow with isoproterenol with no change in cardiac output confirms that beta adrenergic stimulation causes vasodilatation in the uterus.

In spite of the increase in uterine renin secretion after uterine artery ligation, there was a consistent fall in blood pressure and cardiac output. Conceivably, uterine ischemia results not only in the release of renin but also a vasodilator such as a kallikrein or prostaglandin. Human menstrual fluid and uterus contain prostaglandins but whether they are released into the circulation has not been investigated (30). Release of a kallikrein from an ischemic uterus or placenta could result in hypotension in the present experiments and in toxemia, activate intravascular coagulation which has been postulated to be the cause of the glomerular changes (31). Whether the uterus contains kallikrein is not known.

During hemorrhage, blood flow to the uterus was relatively maintained. Although absolute values fell because of the fall in cardiac output, the percentage of cardiac output to the uterus remained constant. Maintenance of uterine blood flow during hemorrhage could be due to elevated angiotensin, since uterine and renal renin release would, if the effect is similar to an angiotensin infusion, increase uterine blood flow. This preservation of uterine blood flow with hemorrhagic hypotension, if it occurs in women, could be a factor in the development of acute renal failure during pregnancy.

The role uterine renin plays in hypertensive states of pregnancy is speculative. Human uterus and amniotic fluid contain renin, but whether it is released with reduction in uterine blood flow is unknown. The only study in which $\mathrm{A}-\mathrm{V}$ differences were obtained in toxemic women at the time of cesarean section demonstrated higher renin concentration in uterine vein than in uterine artery (32). However, the differences and the number of patients studied were small. PRA and aldosterone excretion fall with the onset of toxemia $(33,34)$, but salt retention and increased sensitivity to angiotensin similarly occur (35). The recent finding (36) that angioten$\sin$ receptor-site affinity increases in response to salt loading might be an explanation for the increased sensitivity to angiotensin which occurs with the development of toxemia. The initiating event might be sodium retention secondary to reduction in glomerular filtration rate from the glomerular pathology of toxemia which is not dependent on the development of hypertension (37). Persistent uterine renin secretion under these circumstances might result in hypertension. The reduction in the incidence of toxemia by the use of diuretics would point to salt retention being an important feature in the development of the disease. 


\section{ACKNOWLEDGMENTS}

This investigation was supported by Research Grants HL13653-02 and AM13524-03 from the National Institutes of Health and by grants from the Central Ohio Heart Association and the Bremer Foundation.

\section{REFERENCES}

1. Ferris, T. F., P. Gorden, and P. J. Mulrow. 1967. Rabbit uterus as a source of renin. Am. J. Physiol. 212: 698.

2. Hodari, A. A., O. A. Carretero, and C. P. Hodgkinson. 1969. Uterine production of renin in normal and nephrectomized dogs. Obstet. Gynecol. 34 : 358.

3 Capelli, J. P., L. G. Wesson, Jr., G. E. Aponte, C. Faraldo, and E. Jaffe. 1968. Characterization and source of a renin-like enzyme in anephric humans. J. Clin. Endocrinol. Metab. 28: 221.

4. Symonds, E. M., M. A. Stanley, and S. L. Skinner. 1968. Production of renin by in vitro cultures of human chorion and uterine muscle. Nature (Lond.). 217: 1152.

5. Gorden, P., T. F. Ferris, and P. J. Mulrow. 1967. Rabbit uterus as a possible site of renin synthesis. Am. J. Physiol. 212: 703.

6. Watanabe, M., C. I. Meeker, M. J. Gray, E. A. H. Sims, and S. Solomon. 1963. Secretion rate of aldosterone in normal pregnancy. J. Clin. Invest. 42: 1619.

7. Pickens, P. T., F. M. Bumps, A. M. Lloyd, R. R. Smeby, and I. H. Page. 1965. Measurement of renin activity in human plasma. Circ. Res. 17: 438.

8. Warren, D. J., and T. F. Ferris. 1970. Renin secretion in renal hypertension. Lancet. 1: 159.

9. Metcalfe, J., S. L. Romney, J. R. Swartwout, D. M. Pitcairn, A. N. Lethin, Jr., and D. H. Barron. 1959. Uterine blood flow and oxygen consumption in pregnant sheep and goats. Am. J. Physiol. 197: 929.

10. Huckabee, W. E., J. Metcalfe, H. Prystowsky, and D. H. Barron. 1961. Blood flow and oxygen consumption of the pregnant uterus. Am. J. Physiol. 200: 274.

11. Duncan, S. L. B. 1969. The partition of uterine blood flow in the pregnant rabbit. J. Physiol. (Lond.). 204: 421.

12. Barcroft, J., and P. Rothschild. 1932. The volume of blood in the uterus during pregnancy. J. Physiol. (Lond.). 76: 447.

13. Gould, A. B., L. T. Skeggs, Jr., and J. R. Kahn. 1964. The presence of renin activity in blood vessel walls. $J$. Exp. Med. 119: 389.

14. Barnardo, D. E., C. G. Strong, and W. P. Baldus. 1969. Failure of the cirrhotic liver to inactivate renin: evidence for a splanchnic source of renin-like activity. J. Lab. Clin. Med. 74: 495.

15. Ganten, D., K. Hayduk, H. M. Brecht, R. Boucher, and J. Genest. 1970. Evidence of renin release or production in splanchnic territory. Nature (Lond.). 226: 551.

16. Schaffenburg, C. A., E. Haas, and H. Goldblatt. 1960. Concentration of renin in kidneys and angiotensinogen in serum of various species. Am. J. Physiol. 199: 788.

17. Robb, C. A., J. O. Davis, J. A. Johnson, E. H. Blaine, E. G. Schneider, and J. S. Baumber. 1970. Mechanisms regulating the renal excretion of sodium during pregnancy. J. Clin. Invest. $49: 871$.

18. Brown, J. J., D. L. Davies, P. B. Doak, A. F. Lever, and J. I. S. Robertson. 1966. Serial estimation of plasma renin concentration during pregnancy and after parturition. J. Endocrinol. 35: 373.
19. Hosie, K. F., J. J. Brown, A. M. Harper, A. F. Lever, R. F. MacAdam, J. MacGregor, and J. I. S. Robertson. 1970. The release of renin into the renal circulation of the anesthetized dog. Clin. Sci. (Oxf.). 38: 157.

20. Kaneko, Y., T. Ikeda, T. Takeda, and H. Ueda. 1967. Renin release during acute reduction of arterial pressures in normotensive subjects and patients with renovascular hypertension. J. Clin. Invest. 46: 705.

21. Anderson, R. C., P. N. Herbert, and P. J. Mulrow. 1968. A comparison of properties of renin obtained from the kidney and uterus of the rabbit. Am. J. Physiol. $215: 774$.

22. Mandel, M. J., and L. A. Sapirstein. 1962. Effect of angiotensin infusion on regional blood flow and regional vascular resistance in the rat. Circ. Res. 10: 807.

23. Assali, N. S., L. W. Holm, and N. Sehgal. 1962. Regional blood flow and vascular resistance of the fetus in utero. Action of vasoactive drugs. Am. J. Obstet. Gynecol. 83 : 809.

24. Henning, M., and G. Johnsson. 1967. Interference of phenoxybenzamine and guanethidine with the vasoconstrictor responses of noradrenaline and angiotensin II in the hand. Acta Pharmacol. Toxicol. 25: 373.

25. Scroop, G. C., and R. F. Whelan. 1968. The effects of alpha-adrenergic receptor blockade and sympathetic denervation on the pressor action of angiotensin in man. Aust. J. Exp. Biol. Med. Sci. 46: 563.

26. McGiff, J. C., and T. M. Fasy. 1965. The relationship of the renal vascular activity of angiotensin II to the automatic nervous system. J. Clin. Invest. 44: 1911.

27. Khairallah, P. A., and I. H. Page. 1963. Effects of bradykinin and angiotensin on smooth muscle. Ann. N. Y. Acad. Sci. 104: 212.

28. Krantz, K. E. 1959. Innervation of the human uterus. Ann. N. Y. Acad. Sci. 75: 770.

29. Wansbrough, H., H. Nakanishi, and C. Wood. 1968. The effect of adrenergic receptor blocking drugs on the human uterus. J. Obstet. Gynaecol. Br. Commonw. 75: 189.

30. Von Euler, U. S., and R. Eliason. 1967. Prostaglandins. Academic Press, Inc., New York. 61.

31. Morris, R. H., P. Vassalli, F. K. Beller, and R. T. McCluskey. 1964. Immunofluorescent studies of renal biopsies in the diagnosis of toxemia of pregnancy. $\mathrm{Ob}$ stet. Gynecol. 24 : 32.

32. Smith, R. W., H. E. Selinger, and S. F. Stevenson. 1969. The uteroplacental complex. Am. J. Obstet. Gy necol. 105 : 1129.

33. Brown, J. J., D. L. Davies, P. B. Doak, A. F. Lever, J. I. S. Robertson, and P. Trust. 1965. Plasma renin concentration in hypertensive disease of pregnancy. Lancet. 2 : 1219.

34. Kumar, D., L. A. W. Feltham, and A. G. Gornall. 1959. Aldosterone excretion and tissue electrolytes in normal pregnancy and pre-eclampsia. Lancet. 1: 541.

35. Talledo, O. E., L. C. Chesley, and F. P. Zuspan. 1968. Renin-angiotensin system in normal and toxemic pregnancies. Am. J. Obstet. Gynecol. 100: 218.

36. Brunner, H. R., P. Chang, R. Wallach, J. E. Sealey, and J. H. Laragh. 1972. Angiotensin II vascular receptors: their avidity in relationship to sodium balance, the autonomic nervous system, and hypertension. J. Clin. Invest. 51: 58 .

37. Ferris, T. F., P. B. Herdson, M. S. Dunnill, and $M$. R. Lee. 1969. Toxemia of pregnancy in sheep: a clinical, physiological and pathological study. J. Clin. Invest. 48: 1643. 